\title{
POTENTIALLY PATHOGENIC FREE-LIVING AMOEBAE IN SOME FLOOD-AFFECTED AREAS DURING 2011 CHIANG MAI FLOOD
}

Anchalee WANNASAN, Pichart UPARANUKRAW, Apichart SONGSANGCHUN \& Nimit MORAKOTE

\begin{abstract}
SUMMARY
The survey was carried out to investigate the presence of potentially pathogenic free-living amoebae (FLA) during flood in Chiang Mai, Thailand in 2011. From different crisis flood areas, seven water samples were collected and tested for the presence of amoebae using culture and molecular methods. By monoxenic culture, FLA were detected from all samples at $37{ }^{\circ} \mathrm{C}$ incubation. The FLA growing at $37^{\circ} \mathrm{C}$ were morphologically identified as Acanthamoeba spp., Naegleria spp. and some unidentified amoebae. Only three samples $\left(42.8 \%\right.$ ), defined as thermotolerant FLA, continued to grow at $42^{\circ} \mathrm{C}$. By molecular methods, two non-thermotolerant FlA were shown to have 99\% identity to Acanthamoeba sp. and 98\% identity to Hartmannella vermiformis while the two thermotolerant FLA were identified as Echinamoeba exundans (100\% identity) and Hartmannella sp. (99\% identity). This first report of the occurrence of FLA in water during the flood disaster will provide information to the public to be aware of potentially pathogenic FLA.
\end{abstract}

KEYWORDS: Flood; Chiang Mai; Free-living amoebae.

\section{INTRODUCTION}

Free-living amoebae (FLA) are ubiquitous in nature, mainly in soil and water. Among them, Naegleria, Acanthamoeba, Balamuthia and Sappinia are now known to cause brain infections in humans s,8,27 $^{\text {. }}$ Moreover, Acanthamoeba, Hartmannella and Vahlkampfia can be causative agents of amoebic keratitis in humans ${ }^{1,17}$. Several FLA are also known to play a role as vectors of several intracellular pathogenic microorganisms, such as Legionella pneumophila ${ }^{4}$, Mycobacterium ${ }^{18}$ and Chlamydia-like bacterium ${ }^{20}$ as they can support the growth of those micropathogens and protect them from the harsh environment.

Surveys in Thailand showed the presence of FLA in the environment including water ${ }^{14,16,21}$. Recently, FLA were detected in soil and water samples in Chiang Mai areas ${ }^{34}$. As FLA are abundant in soil, they may be dispersed during flood and as a result human may have increased a risk of getting infected. It is therefore interesting to see if the pathogenic FLA are abundant in water during recent major floods in the country. The present study looked for the occurrence of FLA in the water during the 2011 flood disaster in Chiang Mai, Thailand. The results will provide more useful information to the public so as to have increased awareness of these FLA which can cause severe, life-threatening diseases.

\section{MATERIALS AND METHODS}

Sample collection: At end of September 2011, approximately $50 \mathrm{~mL}$ of water samples were collected from each of seven flood crisis areas in Chiang Mai including Pracha Sampan Intersection (cmf1), Chang Klan Road (cmf2), Nawarat Bridge (cmf3), Chiang Mai-Lampun road (cmf4), Chiang Mai Land Village (cmf5), Nong Hoi Road (cmf6) and Charoen Pratet Road (cmf7) (Fig. 1). Samples were transported to the laboratory in the Department of Parasitology, Faculty of Medicine, Chiang Mai University, and processed on the same day.

Amoebae culture: To detect free-living amoebae, $10 \mu \mathrm{L}$ of the sediment after centrifugation $(1,200 \mathrm{~g}, 10 \mathrm{~min}, \mathrm{RT})$ was dropped onto the middle of NNA-E. coli plates (1.5\% non-nutrient agar pre-coated with heat-inactivated Escherichia coli). The plates were incubated at $37^{\circ} \mathrm{C}$ for two weeks and daily observed for the growth of amoebae using an inverted microscope. If the amoebae existed, Page's amoeba saline solution (PAS) was applied to the culture and amoebae were harvested by scraping the agar surface with spatula. In case of fungal contamination, sub-culturing was performed by cutting the uncontaminated area of agar harboring amoebae and transferring to a new plate. Collected amoebae were subjected to trichrome staining for morphological identification and sub-culturing at $42{ }^{\circ} \mathrm{C}$ in order to examine the thermotolerance characteristics $^{34}$.

Morphological identification: The morphological criteria used to identify amoebae were based on the previous publication ${ }^{30}$. Acanthamoeba cysts are characterized by a double-walled structure with an outer wrinkled wall, while its trophozoite represents fine,

Department of Parasitology, Faculty of Medicine, Chiang Mai University, Chiang Mai, Thailand.

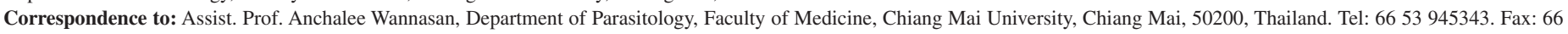
53 945347. E-mail: awannasa@mail.med.cmu.ac.th 


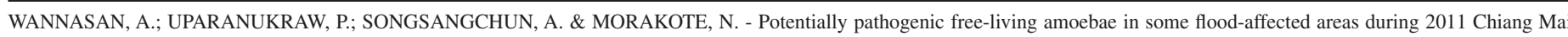
flood. Rev. Inst. Med. Trop. Sao Paulo, 55(6): 411-6, 2013.

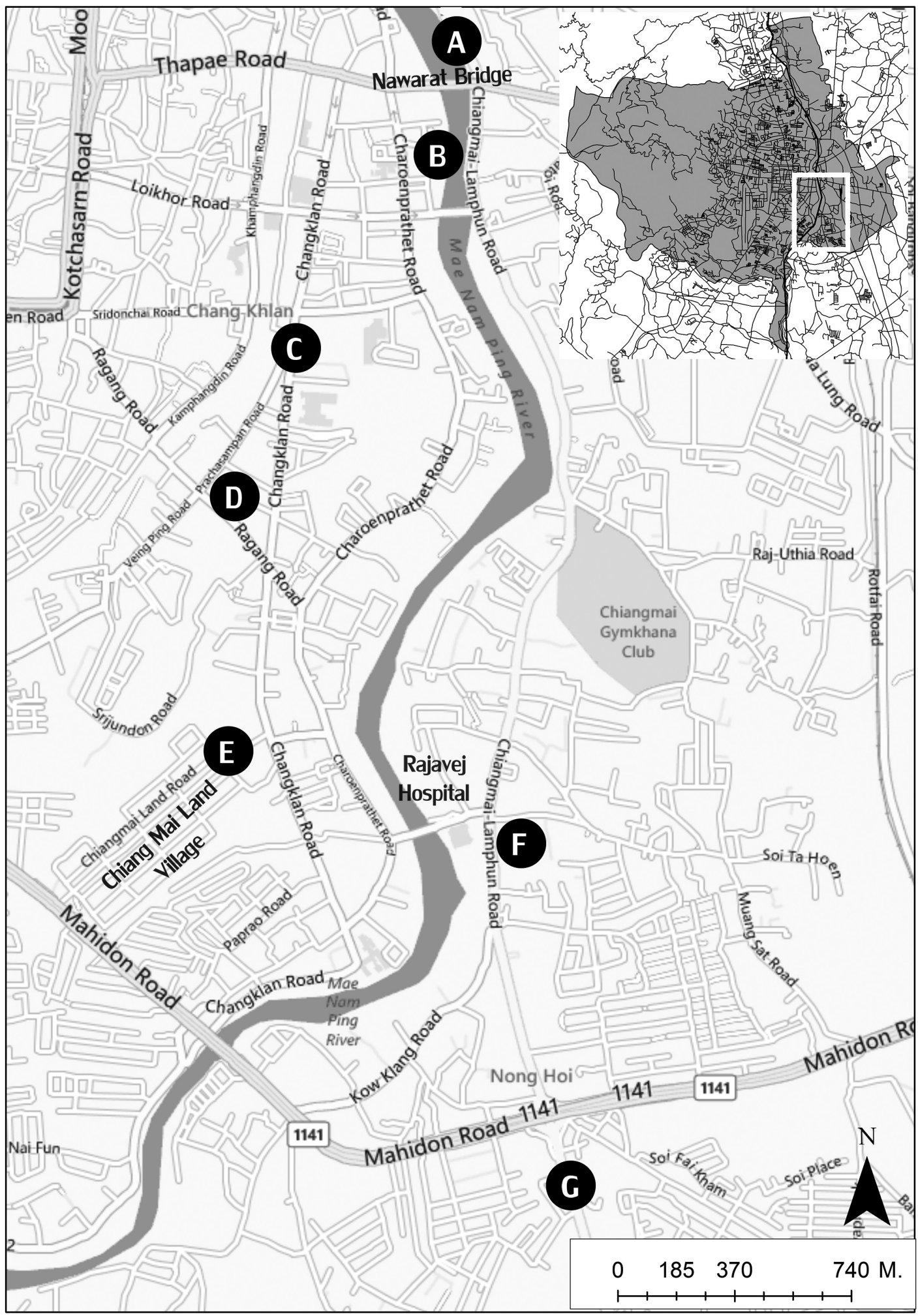

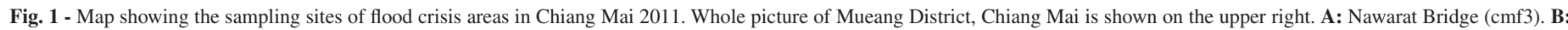

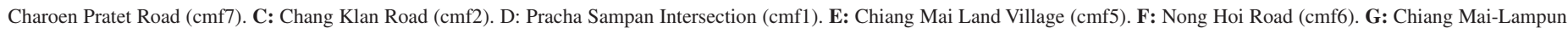
road $(\mathrm{cmf} 4)$. 


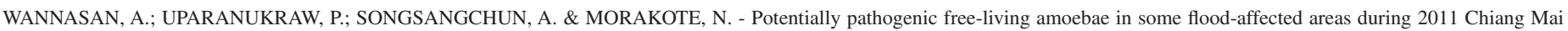
flood. Rev. Inst. Med. Trop. Sao Paulo, 55(6): 411-6, 2013.

tapering, hyaline projections called acanthopodia, Naegleria cyst bears single layer and smooth cyst wall, where as its trophozoite possesses a large karyosome surrounded by a halo and typical blunt pseudopodia, lobopodia ${ }^{30,34}$. Morphological examination and photography were done under a light microscope (Olympus CHA) with 1,000x magnification. Acanthamoeba castellanii originated from a keratitis patient of Siriraj Hospital was used as positive control. Enflagellation experiment was done to verify the presence of Naegleria $\mathrm{spp}^{30}$. Briefly, the suspected trophozoites grown on a NNA-E. coli plate were suspended in sterile distilled water and left at room temperature for at least one hour. The presence of flagellate form containing two long flagella ${ }^{34}$ can be periodically examined under the light microscope.

Molecular identification: DNA preparation was performed by boiling method $^{29}$. In brief, the amoebae were harvested from the culture plates, washed twice with PAS, and centrifuged at 5,000xg for five min at room temperature. After discarding the supernatant, the remaining cell sediment was suspended and directly heated at $95{ }^{\circ} \mathrm{C}$ for $10 \mathrm{~min}$. Following brief centrifugation, $5 \mu \mathrm{L}$ of the supernatant was freshly used for PCR. Whole sediments of the original water samples that showed no growth in culture were heated and used for PCR as described above. Two different sets of PCR employed in this study included FLA PCR designed for the detection of $18 \mathrm{~S}$ rDNA of FLA $^{28}$ and Acanthamoeba spp.-specific PCR (ACA PCR) targeted to $18 \mathrm{~S}$ rDNA of Acanthamoeba ${ }^{24}$. All PCR reactions were done in $50 \mu \mathrm{L}$ reactions containing $5 \mu \mathrm{L}$ of 10x PCR buffer (Fermentas $\left.{ }^{\circledR}\right), 1.25$ units of $i$-Taq ${ }^{\mathrm{TM}}$ DNA polymerase (Fermentas ${ }^{\circledR}$ ) and $0.2 \mathrm{mM}$ of each dNTP (Applied Biosystems). The $\mathrm{MgCl}_{2}$ concentrations were 3 and $4 \mathrm{mM}$ and the primer concentrations were $0.8 \mu \mathrm{M}$ and $0.5 \mu \mathrm{M}$ for FLA PCR and ACA PCR, respectively. For FLA PCR, the reactions were performed by incubation for seven min at $94{ }^{\circ} \mathrm{C}$, followed by 40 cycles of one min at $94{ }^{\circ} \mathrm{C}$, one min at $63{ }^{\circ} \mathrm{C}$ and three $\min 30 \mathrm{~s}$ at $74{ }^{\circ} \mathrm{C}$, with a final extension at $74{ }^{\circ} \mathrm{C}$ for $10 \mathrm{~min}^{28}$. The reaction cycles for ACA PCR were pre-incubation step at seven min at $95^{\circ} \mathrm{C}$, followed by 20 cycles of one min at $95^{\circ} \mathrm{C}$, one min at $60^{\circ} \mathrm{C}$ and two min at $72^{\circ} \mathrm{C}$. This was followed by 25 cycles of one min at $95^{\circ} \mathrm{C}$ and two min at $72{ }^{\circ} \mathrm{C}^{24}$. The PCR was carried out using DNA engine thermal cycler PTC-100 (MJ Research, USA). PCR products were analyzed by electrophoresis on $1.5 \%$ agarose gels and purified using QIAquick PCR purification kit (QIAGEN). The purified PCR products were sent to $1^{\text {st }}$ Base DNA sequencing services (Singapore) for sequencing at both directions using the same primers used in the same PCR. The obtained sequencing data were compared with all published sequences in GenBank using BLASTn at National Center for Biotechnology Information [http:// blast.ncbi.nlm.nih.gov/] and submitted to the GenBank database.

\section{RESULTS}

Agar plate culture: At $37{ }^{\circ} \mathrm{C}$ culture, all seven water samples collected from the flood affected areas showed FLA growth on the second day of incubation. The growth areas of FLA, as shown by the presence of clear zones on $1.5 \%$ NNA-E. coli plates, were then cut and sub-cultured at $42{ }^{\circ} \mathrm{C}$. Three out of seven samples (42.8\%) were able to grow at $42{ }^{\circ} \mathrm{C}$ (Table 1$)$.

Morphological identification: The amoebae growing at $37{ }^{\circ} \mathrm{C}$ were collected and subjected to trichrome staining. Acanthamoeba and Naegleria were concurrently found in most of the flood samples (5/7, $71 \%$ ) stained with trichrome. Acanthamoeba sp. (Fig. 2A) were observed in five samples (except cmf6 and cmf7), while Naegleria sp. (Fig. 2B) were detected in six samples (except cmf6). The presence of Naegleria spp. in six samples was in correspondence with positive enflagellation test (Table 1). Acanthamoeba-like trophozoites showing fine short acanthopodia were also detected (Fig. 2C). Additionally, morphologically unidentified FLA including round double-walled cysts bearing one nucleus with central karyosome (Fig. 2D, E), small round cysts with unstained nucleus (Fig. 2F), small trophozoites presenting short spiny pseudopodia resembling Echinamoeba (Fig. 2G, H) and Hartmannellalike trophozoites with elongated shape (Fig. 2I) were often seen.

Molecular identification: The amoebae growing on agar culture plate at $42{ }^{\circ} \mathrm{C}$ or $37^{\circ} \mathrm{C}$ were harvested and identified by PCR. Using the FLA PCR screening, cmf1 yielded a DNA fragment of approximately 1,000 bp (Fig. 3), whereas $\mathrm{cmf} 3$ to $\mathrm{cmf} 6$ yielded a distinctive band at $800 \mathrm{bp}$. However, cmf 2 and $\mathrm{cmf} 7$ were negative by FLA PCR. When the ACA PCR was employed, the approximately 500-bp specific band for Acanthamoeba spp. was observed only in cmf1 (Fig. 4). Purified PCR products obtained from ACA PCR ( $\mathrm{cmf} 1)$ and FLA PCR ( $\mathrm{cmf} 3$, cmf4, cmf5 and cmf6) were used for sequencing. Results from BLASTn revealed that sequence from cmf1 belonged to Acanthamoeba sp. (99\% maximum identity with Acanthamoeba sp. UNB13 from Brazil Accession No. JQ268234, followed by $96 \%$ maximum identity with Acanthamoeba castellanii Accession No. GU001160). FLA isolated from cmf4 was

Table 1

FLA detected during 2011 Chiang Mai flood

\begin{tabular}{|c|c|c|c|c|c|c|}
\hline Isolate & Growth at $37^{\circ} \mathrm{C}$ & Growth at $42^{\circ} \mathrm{C}$ & Enflagellation test & FLA-PCR & ACA-PCR & Sequencing data \\
\hline $\mathrm{cmf1}$ & $\mathrm{G}^{\mathrm{a}}$ & $\mathrm{NG}^{\mathrm{b}}$ & + & Pos & Pos & Acanthamoeba sp. \\
\hline $\mathrm{cmf} 2$ & $\mathrm{G}$ & $\mathrm{NG}$ & + & $\mathrm{Neg}$ & Neg & $\mathrm{ND}^{\mathrm{c}}$ \\
\hline $\mathrm{cmf} 3$ & $\mathrm{G}$ & $\mathrm{G}$ & + & Pos & $\mathrm{Neg}$ & Invalid data \\
\hline $\operatorname{cmf} 4$ & G & G & + & Pos & Neg & Echinamoeba sp. \\
\hline cmf5 & $\mathrm{G}$ & $\mathrm{G}$ & + & Pos & Neg & Hartmannella sp. \\
\hline cmf6 & G & $\mathrm{NG}$ & - & Pos & $\mathrm{Neg}$ & Hartmannella sp. \\
\hline $\mathrm{cmf} 7$ & $\mathrm{G}$ & NG & + & $\mathrm{Neg}$ & $\mathrm{Neg}$ & ND \\
\hline
\end{tabular}

${ }^{\text {a }}$ G: growth, ${ }^{\mathrm{b}} \mathrm{NG}$ : no growth, ${ }^{\mathrm{c}} \mathrm{ND}$ : not done. 


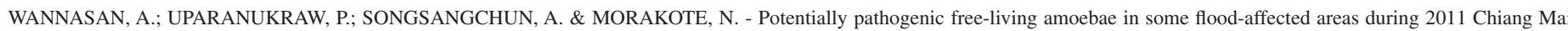
flood. Rev. Inst. Med. Trop. Sao Paulo, 55(6): 411-6, 2013.

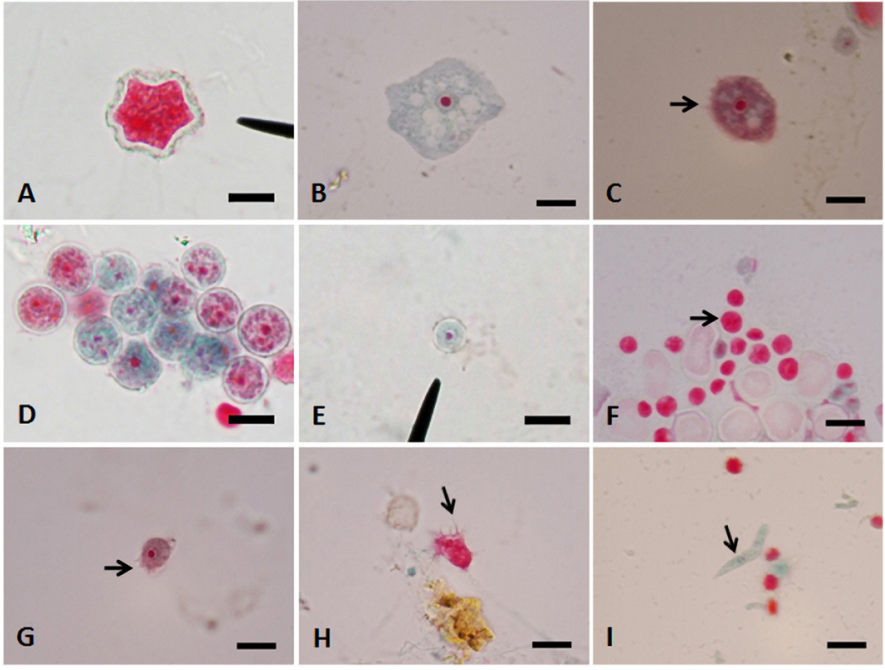

Fig. 2 A-I - Trichrome staining of free-living amoebae under light microscopy (1,000x), bar $=10 \mu \mathrm{m}$. A: A cyst of Acanthamoeba sp. B: A large trophozoite of Naegleria sp. C: Acanthamoeba-like trophozoites (arrow showing fine short acanthopodia). D, E: Different sizes of unidentified double-walled cysts with distinct nuclei. F: Unidentified amoebae with small round cysts (arrow). G, H: Small Echinamoeba-like trophozoites (arrow showing few spiny short pseudopodia). I: An elongated cylindrical trophozoite of Hartmannella-like amoeba (arrow).

Echinamoeba exundans (100\% identity with E. exundans Accession No. AF293895), while those from $\mathrm{cmf} 5$ and cmf6 were most closely related to Hartmannella sp. (Accession No. HM363627) and Hartmannella vermiformis (Accession No. FJ940709) with 99 and 98\% maximum identity, respectively. On the other hand, we failed to obtain unambiguous sequencing data from $\mathrm{cmf} 3$. It was also impossible to further analyze FLA isolated from $\mathrm{cmf} 2, \mathrm{cmf} 3$ and $\mathrm{cmf} 7$ since they were lost during culture. The sequences of FLA reported in this study were deposited in GenBank (Accession Number: JX507295-JX507297).
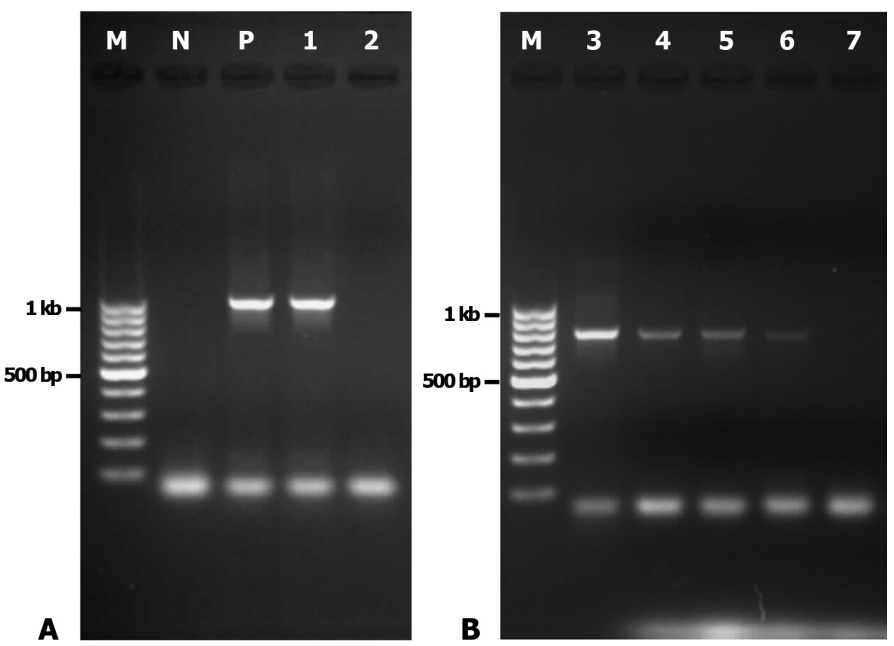

Fig. 3 - Gel electrophoresis of amplicons from FLA PCR conditions. A: N - negative control. Lane $\mathrm{P}$ (positive control) and lane 1 (cmf1) showing the specific bands (1 kb) for Acanthamoeba. Lane 2 (cmf2) showing negative result. B: Lanes 3, 4, 5 and 6 (cmf3, cmf4, cmf5 and cmf6, respectively) showing the bands ( $800 \mathrm{bp})$ for other free-living amoebae. Lane 7 (cmf7) showing negative result. M - 100 bp Ladder DNA (Fermentas ${ }^{\circledR}$ ).

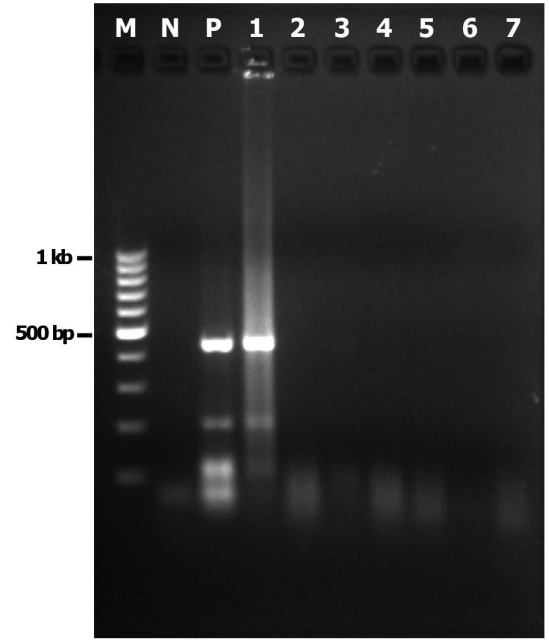

Fig. 4 - Gel electrophoresis of amplicons from ACA PCR conditions. N - negative control Lane $\mathrm{P}$ (positive control) and lane 1 ( $\mathrm{cmf} 1$ ) showing the approximately specific bands (500bp) for Acanthamoeba. Lanes 2, 3, 4, 5, 6 and 7 (cmf2, cmf3, cmf4, cmf5, cmf6 and cmf7, respectively) showing negative results. M - 100 bp Ladder DNA (Fermentas ${ }^{\circledR}$ ).

\section{DISCUSSION}

In Thailand, at least 17 cases of human brain infection caused by Acanthamoeba, Naegleria and Balamuthia ${ }^{13,25,35}, 29$ cases of acanthamoebic keratis ${ }^{6,15,33}$, and one case of Acanthamoeba infection of gastric ulcer ${ }^{26}$ have been reported from several provinces. Although there has never been any case of brain infection due to FLA reported from Chiang Mai, the importance of FLA cannot be neglected. In the previous survey of natural water sources in Chiang Mai in 2009, FLA frequently found were Naegleria spp. (37.5\%) and Acanthamoeba spp. $(18.8 \%)$. The number of positive thermotolerant FLA from water samples $(62.5 \%)$ was higher than that from soil samples $(37.5 \%)^{34}$. As far as the flood conditions are concerned, such potentially pathogenic FLA in the environment may disperse and increase during the flood. Surprisingly, neither thermotolerant Naegleria nor Acanthamoeba was found in the present survey. Although the number of samples in the present study was low, detection of thermotolerant FLA were demonstrated in three out of seven water samples analyzed.

To our knowledge, this is the first report of the occurrence of FLA during flood disaster in Thailand. It was not surprising that several amoebae including Acanthamoeba and Naegleria were detected by microscopic examination after $37^{\circ} \mathrm{C}$ incubation in all flood water samples. The presence of Acanthamoeba and Naegleria in this survey is due to their abundance in nature and ability to dwell in unsanitary conditions. However, both Acanthamoeba and Naegleria isolated from the flood samples failed to grow at $42{ }^{\circ} \mathrm{C}$. This was unexpected as the previous FLA survey in Chiang Mai showed the occurrence of both thermotolerant Acanthamoeba and Naegleria in water and soil samples ${ }^{34}$. Instead, thermotolerant Hartmannella and Echinamoeba were identified for the first time in Chiang Mai in this survey.

In the present study, five out of seven samples were successfully amplified by FLA PCR. The usefulness of FLA PCR, of which its primers are targeted at the conserved regions of Acanthamoeba $18 \mathrm{~S}$ rDNA, was stated in some studies showing a detection range of several 


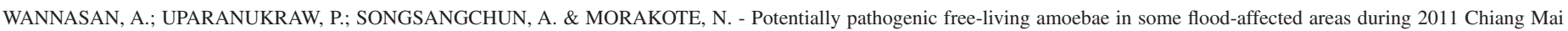
flood. Rev. Inst. Med. Trop. Sao Paulo, 55(6): 411-6, 2013

FLA such as Naegleria, Acanthamoeba, Hartmannella, Vahlkampfia ${ }^{28}$, Echinamoeba, Vannella and Protacanthamoeba ${ }^{9}$ and also ciliated freshwater protozoan Tetrahymena ${ }^{3}$. The negative results of FLA PCR in two of the flood samples might in part be due to the presence of unknown FLA which could not be detected by this PCR. The discrepancy between the sequencing data and microscopic examination and enflagellation test (Table 1) might be the result of sub-culturing procedures that lead to the overgrowth of predominant FLA. Moreover, some samples used for DNA preparation were harvested from continuous sub-culturing, not from the first inoculation as done for microscopic examination. Therefore, FLA detected by PCR could be only the subset of population of the entire samples. In contrast, FLA detected by microscopic examination represented the amoebae grown on the whole culture plates. Regarding cmf3, despite a distinct band obtained by FLA PCR, we could not get the valid sequencing data. It is possible that more than one species of amoebae were present in $\mathrm{cmf} 3$ resulting in heterogeneous PCR products and hence ambiguous sequence. In such a failure, axenic culture or cloning by limiting dilution should be considered in future surveys.

Among the non-thermotolerant FLA, only cmf1 and cmf6 were successfully sequenced showing the close relationship to Acanthamoeba sp. and Hartmannella vermiformis, respectively. The FLA isolated from cmf1 was most similar to Acanthamoeba sp. (JG268234, 99\% identity). It also had $96 \%$ identity to Acanthamoeba castellanii (GU001160). It is widely accepted that temperature tolerance is a characteristic of potential pathogenicity, particularly for Acanthamoeba ${ }^{10,31}$. It is therefore unlikely that Acanthamoeba identified in this study is virulent. As for Hartmannella, no evidence supporting correlation between thermotolerance and pathogenicity has been demonstrated but the health impact of non-thermotolerant Hartmannella could not be ignored.

Among the three thermotolerant FLA detected in this study, cmf4 and cmf5 were successfully sequenced and identified as Echinamoeba exundans and Hartmannella sp., respectively. Although Echinamoeba has been occasionally reported from aquatic sources, e.g. lake, leaf litter ${ }^{22}$, hot water systems of hospitals ${ }^{23}$, water bodies ${ }^{9}$ and hot springs ${ }^{2}$. To our knowledge this genus has never been described as a human pathogen. Hartmannella is ubiquitous in nature and has recently been associated with amoebic keratitis as it was found to co-infect with Acanthamoeba or even with Vahlkampfia ${ }^{1,12,17}$. Even if Echinamoeba and Hartmannella of thermotolerant isolates investigated in this study are not considered to be as serious as Acanthamoeba or Naegleria, their important role as potential vectors of pathogens could not be overlooked. Acanthamoeba, Echinamoeba and Hartmannella have been reported to serve as vectors harboring several human pathogenic bacteria, such as, Legionella pneumophila $^{4,9}$, Exophiala dermatitidis ${ }^{5}$, Pseudomonas aeruginosa ${ }^{9,19}$, Comamonas acidovorans, Escherichia coli, Proteus mirabilis, Vibrio cholerae $^{32}$ and Mycobacterium ${ }^{11}$. Thus the findings of such amoebae in this survey during flood in Chiang Mai should provide evidence for awareness of outbreaks of human infections caused by these FLA.

\section{RESUMO}

\section{Amebas potencialmente patogênicas de vida livre em algumas áreas afetadas durante a inundação de 2011 em Chiang Mai}

A pesquisa foi feita para investigar a presença de amebas de vida livre (FLA) durante a inundação em Chiang Mai, Tailândia, ano de
2011. A partir de diferentes áreas de inundação sete amostras de água foram coletadas e testadas para a presença de amebas usando métodos moleculares e de cultura. Através da cultura monoxênica, FLA foi detectada em todas as amostras após incubação a $37{ }^{\circ} \mathrm{C}$. As FLA crescendo a $37{ }^{\circ} \mathrm{C}$ foram identificadas morfologicamente como Acanthamoeba spp, Naegleria spp e algumas amebas não determinadas. Somente três amostras $(42,8 \%)$ definidas como FLA termotolerantes continuaram a crescer a $42{ }^{\circ} \mathrm{C}$. Por métodos moleculares duas FLA termotolerantes tiveram $99 \%$ de identidade com a Acanthamoeba sp e 98\% de identidade com Hartmannella vermiformis enquanto as duas FLA termotolerantes foram identificadas como Echinamoeba exundans (100\% de identidade) e Hartmannella sp (99\% de identidade). Este primeiro relato da ocorrência de FLA em águas durante inundações informa ao público que ele deve estar atento de FLA potencialmente patogênica.

\section{ACKNOWLEDGEMENTS}

This study was financially supported by the Faculty of Medicine Endowment Fund for Medical Research, Chiang Mai University. The authors thank Assist. Prof. Koson Roongruangchai for providing the Acanthamoeba castellanii positive control used in this study and Mr. Pathamet Khositharattanakool, Ms. Rungkanta Methanitikorn for their help in producing the map and pictures. The authors acknowledge Regional Centre for Geo-informatics and Space Technology (North), Faculty of Social Sciences, Chiang Mai University for the information and the maps of the affected areas during the 2011 Chiang Mai flood.

\section{REFERENCES}

1. Aitken D, Hay J, Kinnear FB, Kirkness CM, Lee WR, Seal DV. Amebic keratitis in a wearer of disposable contact lenses due to a mixed Vahlkampfia and Hartmannella infection. Ophthalmology. 1996;103:485-94.

2. Baumgartner M, Yapi A, Gröbner-Ferreira R, Stetter KO. Cultivation and properties of Echinamoeba thermarum n. sp., an extremely thermophilic amoeba thriving in hot springs. Extremophiles. 2003;7:267-74.

3. Behets J, Declerck P, Delaedt Y, Verelst L, Ollevier F. Survey for the presence of specific free-living amoebae in cooling waters from Belgian power plants. Parasitol Res. 2007;100:1249-56.

4. Brieland J, McClain M, LeGendre M, Engleberg C. Intrapulmonary Hartmannella vermiformis: a potential niche for Legionella pneumophila replication in a murine model of legionellosis. Infect Immun. 1997;65:4892-6.

5. Cateau E, Mergey T, Kauffmann-Lacroix C, Rodier MH. Relationships between free living amoebae and Exophiala dermatitidis: a preliminary study. Med Mycol. 2009;47:115-8.

6. Chuckpaiwong V, Vathesatokkit C, Lekhanont K, Vongthongsri A. Acanthamoeba keratitis: character and outcome of treatment in tropical area. Thai J Opthalmol. 2010;24:26-36.

7. Gelman BB, Popov V, Chaljub G, Nader R, Rauf SJ, Nauta HW, et al. Neuropathological and ultrastructural features of amoebic encephalitis caused by Sappinia diploidea. J Neuropathol Exp Neurol. 2003;62:990-8.

8. Gelman BB, Rauf SJ, Nader R, Popov V, Bokowski J, Chaljub G, et al. Amoebic encephalitis due to Sappinia diploidea. JAMA. 2001;285:2450-541.

9. Gianinazzi C, Schild M, Wuthrich F, Ben NN, Fuchslin HP, Schurch N, et al. Screening Swiss water bodies for potentially pathogenic free-living amoebae. Res Microbiol. 2009; 160:367-74. 
WANNASAN, A.; UPARANUKRAW, P.; SONGSANGCHUN, A. \& MORAKOTE, N. - Potentially pathogenic free-living amoebae in some flood-affected areas during 2011 Chiang Mai flood. Rev. Inst. Med. Trop. Sao Paulo, 55(6): 411-6, 2013.

10. Griffin JL. Temperature tolerance of pathogenic and nonpathogenic free-living amoebas. Science. 1972;178(4063):869-70.

11. Gryseels S, Amissah D, Durnez L, Vandelannoote K, Leirs H, De Jonckheere J, et al. Amoebae as potential environmental hosts for Mycobacterium ulcerans and other mycobacteria, but doubtful actors in Buruli ulcer epidemiology. PLoS Negl Trop Dis. 2012;6:e1764.

12. Inoue T, Asari S, Tahara K, Hayashi K, Kiritoshi A, Shimomura Y. Acanthamoeba keratitis with symbiosis of Hartmannella ameba. Am J Ophthalmol. 1998;125:721-3.

13. Intalapaporn P, Suankratay C, Shuangshoti S, Phantumchinda K, Keelawat S, Wilde H. Balamuthia mandrillaris meningoencephalitis: the first case in southeast Asia. Am J Trop Med Hyg. 2004;70:666-9.

14. Jariya P, Tiewchalore S, Junne V, Lertlaituan P, Suvithayasri V. Survey of Naegleria fowleri the causative agent of primary amoebic meningoencephalitis (PAM) in stagnant waters around factory area in Thailand. Siriraj Med J. 1997;49:222-9.

15. Korriruvongs P, Wanachiwanawin D, Visvesvara GS. Treatment of Acanthamoeba keratitis with chlorhexidine.Opthalmology. 1999;106:798-802.

16. Lekkla A, Sutthikornchai C, Bovornkitti S, Sukthana Y. Free-living ameba contamination in natural hot springs in Thailand. Southeast Asian J Trop Med Public Health. 2005;36(Suppl 4):5-9.

17. Lorenzo-Morales J, Martinez-Carretero E, Batista N, Varez-Marin J, Bahaya Y, Walochnik $\mathbf{J}$, et al. Early diagnosis of amoebic keratitis due to a mixed infection with Acanthamoeba and Hartmannella. Parasitol Res. 2007;102:167-9.

18. Marciano-Cabral F, Jamerson M, Kaneshiro ES. Free-living amoebae, Legionella and Mycobacterium in tap water supplied by a municipal drinking water utility in the USA. J Water Health. 2010;8:71-82.

19. Michel R, Burghardt H, Bergmann H. Acanthamoeba, naturally intracellularly infected with Pseudomonas aeruginosa, after their isolation from a microbiologically contaminated drinking water system in a hospital. Zentralbl Hyg Umweltmed. 1995;196:532-44

20. Michel R, Müller KD, Zöller L, Walochnik J, Hartmann M, Schmid EN. Free-living amoebae serve as a host for the Chlamydia-like bacterium Simkania negevensis. Acta Protozool. 2005;44:113-21.

21. Nacapunchai D, Kino H, Ruangsitticha C, Sriwichai P, Ishih A, Terada M. A brief survey of free-living amebae in Thailand and Hamamatsu District, Japan. Southeast Asian J Trop Med Public Health. 2001;32(Suppl 2):179-82.

22. Page FC. A new family of amoebae with fine pseudopodia. Zool J Linn Soc. 1975;56:73-89

23. Rohr U, Weber S, Michel R, Selenka F, Wilhelm M. Comparison of free-living amoebae in hot water systems of hospitals with isolates from moist sanitary areas by identifying genera and determining temperature tolerance. Appl Environ Microbiol. 1998;64:1822-4.
24. Schroeder JM, Booton GC, Hay J, Niszl IA, Seal DV, Markus MB, et al. Use of subgenic $18 \mathrm{~S}$ ribosomal DNA PCR and sequencing for genus and genotype identification of Acanthamoebae from humans with keratitis and from sewage sludge. J Clin Microbiol. 2001;39:1903-11.

25. Siripanth C, Punpoowong B, Riganti M. Early detection and identification of amphizoic amoebae from nasal exudates of a symptomatic case. J Med Assoc Thai. $2005 ; 88: 545-9$

26. Thamprasert K, Khunamornpong S, Morakote N. Acanthamoeba infection of peptic ulcer. Ann Trop Med Parasitol. 1993;87:403-5.

27. Trabelsi H, Dendana F, Sellami A, Sellami H, Cheikhrouhou F, Neji S, et al. Pathogenic free-living amoebae: epidemiology and clinical review. Pathol Biol (Paris). 2012;60:399-405.

28. Tsvetkova N, Schild M, Panaiotov S, Kurdova-Mintcheva R, Gottstein B, Walochnik $\mathrm{J}$, et al. The identification of free-living environmental isolates of amoebae from Bulgaria. Parasitol Res. 2004;92:405-13.

29. Uparanukraw P, Morakote N. Detection of circulating Trichinella spiralis larvae by polymerase chain reaction. Parasitol Res. 1997;83:52-6.

30. Visvesvara GS. Pathogenic and opportunistic free-living amoebae. In: Murray PR Baron EJ, Pfaller MA, Tenover FC, Yolken RH, ed. Manual of clinical microbiology. $7^{\text {th }}$ ed. Washington DC: ASM Press; 1999. p. 1383-90.

31. Walochnik J, Haller-Schober E, Kolli H, Picher O, Obwaller A, Aspock H Discrimination between clinically relevant and nonrelevant Acanthamoeba strains isolated from contact lens- wearing keratitis patients in Austria. J Clin Microbiol. 2000;38:3932-6

32. Walochnik J, Picher O, Aspöck C, Ullmann M, Sommer R, Aspöck H. Interaction of "Limax amoebae" and gram-negative bacteria: experimental studies and review of current problems. Tokai J Exp Clin Med. 1998;23:273-8.

33. Wanachiwanawin D, Booranapong W, Kosrirukvongs P. Clinical features of Acanthamoeba keratitis in contact lens wearers and non-wearers. Southeast Asian J Trop Med Public Health. 2012;43:549-56.

34. Wannasan A, Chaiwong P, Bunchoo M, Morakote N. Occurence of thermotoleran Naegleria and Acanthamoeba in some natural water sources in Chiang Mai. Chiang Mai Med J. 2009;48:117-24.

35. Wiwanitkit V. Review of clinical presentations in Thai patients with primary amoebic meningoencephalitis. MedGenMed. 2004;6:2.

Received: 19 October 2012

Accepted: 13 March 2013 